\title{
STUDIES ON FOOD, HEALTH AND ENVIRONMENTAL PERSPECTIVES IN MULBERRY (MORUS SPP.) - A REVIEW
}

\author{
MS Rahman ${ }^{1,2}$ and SMS Islam ${ }^{1 *}$ \\ 1Plant Biotechnology and Genetic Engineering Lab., Institute of Biological Sciences, University of Rajshahi, \\ Rajshahi-6205, Bangladesh \\ 2Bangladesh Sericulture Development Board, Baliapukur, Rajshahi, Bangladesh
}

\begin{abstract}
Mulberry is a very hard and quickly developing plant belongs to the family of Moraceae. The leaf of mulberry is exclusively utilized for feeding and rising of the silkworm (Bombyx mori) for the production of silk yarn. It is evaluated that mulberry silk contributes around $90 \%$ of the total worldwide raw silk production that contributed to socio-economic development worldwide. The usage of mulberry leaves as silkworm feed, it is being utilized for food and medicinal purpose also. For instance, the mulberry fruit because of its high nutritive value and flavorful taste is getting significance as important foodstuff. The mulberry bark and wood are likewise helpful for assembling of paper and sports products things. Mulberry is a quickly developing with profound roots, flourish leaves, high protections from pollution, wind, sand, drought, and salinity with strong adaptability and simple cultivation. The broad environmental adaptability of mulberry to light, temperature, water, soil and other normal conditions objectively empowers it to have numerous environmental defensive capacities in water and soil protection, wind tolerance and sand consolidation, water source preservation, and air refreshment. Since earlier, Ayurveda and other literature have claimed the diverse medicinal properties against certain serious diseases e.g. hypertension, hyperglycemia, cancer, arthritis, diabetes and rheumatis, heart disease, inflammation, fever, cough and throat, stomach related disease, unsteadiness, hepatitis etc. The current studies of different pharmacological compounds of medicinal significance present in mulberry plants opens up new avenues of research in the medical science. Under this study briefly described about economic as well as environmental importance of mulberry taking into account different aspects of its role as animal feed, foodstuff, phytomedicine and remediation of polluted soils and atmosphere, etc.
\end{abstract}

Key words: Economic importance, Environmental protection, Medicinal properties (Morus spp).

\section{Introduction}

The mulberry is a quickly developing hardy perennial woody plant belongs to the family Moraceae (Pan and Lou 2008, Yang et al. 2010). The plants are cultivated under both tropical and temperate climatic conditions of different regions in Bangladesh (Rahman and Islam 2020a). It has numerous significant qualities like higher foliage yield, shorter growth period and more environmental adaptability etc. Generally, more than 15 species of the genus Morus are found in sub-tropical, tropical and temperate regions of Asia, Africa and North America (Pérez-Gregorio et al. 2011). The important ones incorporate M. alba, M. nigra, M. rubra, M.

*Author for correspondence: shahinul68@gmail.com/ serajbsdb12@gmail.com 
australis, M. atropurpurea, M. cathayana, M. notabilis and M. mesosygia. Mulberry is broadly perceived for its socio-economic significance. Leaves of mulberry plant are broadly utilized for the primary and only food of silkworm (Bombyx mori L.) for the production of silk yarn (Rahman and Islam 2020b). Mainly, the protein contained in the mulberry leaf is converted into the silk protein (fibroin and sericin) by the silkworm. The silk in this manner, delivered is utilized commercially for making great silk garments. It is assessed that mulberry silk contributes around $90 \%$ of the total worldwide raw silk production, causing essentially to the employments of various people over the globe. Aside from this, numerous nutritional advantages and medicinal benefits are credited to the mulberry plant. The mulberry leaves and fruits rich in protein and vitamins are long being exploited as creature feed/food items different countries. A few investigations have indicated antioxidant, antiviral, anti-inflammatory, hypolipidemic, against hyperglycemic, neuroprotective (Pan and Lou 2008), anti-HIV, anti- hypotensive and cytotoxic activities of various types of Morus (Du et al. 2003). The leaves of $M$. alba gave with valuable phytochemicals, for example, coumarins, flavonoids and phenols are seen as helpful in reducing blood pressure and cholesterol level in human body (Sheng-Qin and Wu 2003, Zhang et al. 2009). A wildly developing rural mulberry plant, M. nigra is accounted to have medicinal benefits especially in treating arthritis, diabetes and rheumatis (Pérez-Gregorio et al. 2011). Two new flavonoids have likewise been separated from the leaves of this plant species (Wang et al. 2009). The phytochemical constituents separated from the leaves and fruits of $M$. rubra been accounted (Sharma et al. 2010). Currently, the cancer prevention agent of the extracts got from various mulberry plant parts leaves, branches, viz. roots and fruits was examined by a few scientists (Andallu et al. 2001, Andallu and Varadacharyulu 2002, Arfan et al. 2012). Among the 28 fruits ordinarily consumed in China, mulberry mash was characterized by one of the highest values of the ferric reducing antioxidant power (FRAP) at $4.11 \mathrm{~m}$. $\mathrm{mol} / 100 \mathrm{~g}$ wet weight (Guo et al. 2003). Mulberry fruit juice is used to dispose of impurities from the body and to cure heart problem, dried fruit powder functions as an anti-mutagen which can inhibit the mutation of healthy typical cells into cancers cells (Nazim et al. 2017). At present, the event of expanded level of poisonous toxins to the air, soil and ground water has made genuine dangers the earth, environment and human health. It might be because of fast industrialization, deforestation, transportation and over concentrated urban population. The use of perennial woody mulberry plant with its striking highlights features like broad root system, high biomass production and strong ecological adaptability exhibited an encouraging result to balance the adverse impacts of heavy metals in the diverse contaminated soils (Peng et al. 2012, Delplanque et al. 2013, Zhou et al. 2015). Mulberry leafs with its strong absorption capacity to be valuable in controlling atmospheric pollution. The water maintenance capacity in the mulberry garden is accounted to be higher than that of the open land. This paper reviews the economic and environmental importance of mulberry taking into account several aspects of its role as animal feed, foodstuff, phytomedicine and remediation of polluted soils and atmosphere etc.

\section{Economic importance of mulberry}

Mulberry has been cultivated in different countries with economic importance for earlier with the sole reason for feeding the monophagous silkworm (Bombyx mori L.). Mainly, the protein contained in the mulberry leaf is transferred into the silk protein (fibroin and sericin) by the silkworm. Moreover the significant usage of mulberry leaves as silkworm feed, it is being utilized for some other purposes. The importance of mulberry as animal feed and its medicinal benefits has been mostly recognized (Sujathamma et al. 2013). This section describe about different economical utilization of mulberry.

\subsection{Production of silk yarn}

Mulberry is a natural tree and brings great environmental advantage as well as yields high economic earning. The mulberry plant is the main food to silkworm (Bombyx mori L.) which produces silk, the queen of textiles (Wani et al. 2017). Mainly, the protein contained in the mulberry leaf is transferred into the silk protein (fibroin 
and sericin) by the silkworm. It is assessed that mulberry silk contributes around $90 \%$ of the total worldwide raw silk production, helping significantly to the occupations of various peoples over the globe (Ghosh et al. 2017). The leaf of the mulberry is one of the major food for silkworm and the achievement and profitability of silk, quality mulberry leaf upgrades the efficiency of cocoon and quality of silk (Ashiru 2002, Doss et al. 2012, Rahman and Islam 2020b). About 68 species Morus have been extensively identified (Datta 2000), of which M. alba, M. latifolia, M. mutlicaulis are grown for leaves for production of silk (Vijayan et al. 2011).

\subsection{Poverty alleviation through employment generation in mulberry cultivation for sericulture}

Sericulture is one of the essential occupations for employment of poor people. It is an incredibly labor intensive industry and possesses a pivotal situation from the point of giving employment and extra earning to more fragile segments on the planet and semi urban population (Bhatta and Rao 2003, Best and Maier 2007). Sericulture, the production of silk cocoon and in this way the finish product of silk fiber (Ganga and Chetty 1991), has become a promising rural activities in India and also in Bangladesh on account of its minimum gestation period, minimal investment, maximum employment generation and quick turnover for investment (Eswarappa 2000, $2009 \mathrm{a \& b})$. One hectare of mulberry sericulture land can make profitable work for 13 people per year (Datta 1988). Sericulture is a cash crop in the agriculture segment; it gives returns within 30 days, so these assistance to marginal peoples for the socio-economic changes. In sericulture, the whole scope of activities produce a moderate flow of earning and makes employment generation for a considerable area of low skilled marginal rural occupants who might somehow or another stay jobless or disguised employed in vast agricultural segment. These segments are farm work based and fall under the house and little scope segment (Dewangan 2017). In silkworm seed segments, mulberry cultivation makes employment on farm. The silkworm raising segment utilizes mulberry leaves as input and this makes huge scope of work and earning capacity for the family of mulberry producers. The making of work and earning in silk reeling units is dealt with in (Radhakrishna et al. 2000) where they found that an acre of land of mulberry creates as much as one lakh rupees for each year (6500\$) through exchanges of cocoon and give full work to at least 5 men round the year. Sericulture with its unique features assumes a significant role in upgrading the socio-economic situations of the rural folk and with employment opportunities to the educated rural youth and women. Sericulture is a way for creates employment generation and needs as they act as a tool for socio-economic change.

\subsection{Mulberry as foodstuff}

Mulberry fruits are consumable and notable for its delicious taste. They can be consumed directly or can be utilized in the preparation of wine, jam or soft drink. Mulberry fruits have numerous nice characters like decent taste, moderate size, attractive colour and high nutritive and medicinal benefits. Mulberries are a literal powerhouse of nutrition. They are rich in Vitamins B, C, K and the component iron. Good levels of fiber, riboflavin, phosphorus, copper, magnesium and potassium are likewise found in mulberries. Additionally they are an excellent source of antioxidant resveratrol, zeaxanthin, lutein, and less significantly the alpha and beta carotene. Fresh mulberry fruits are rich in amino acids, vitamins and mineral, for example, $\mathrm{Zn}, \mathrm{Mn}, \mathrm{Fe}, \mathrm{Ca}$ that are essential for the human body. Likewise, mulberry fruits additionally pectin and fibrin. The usage of mulberry fruits as colouring and flavoring agent was likewise investigated (Kumar et al. 1995). All around matured mulberry fruits are sweet and are offered in the Indian market as a fruit dish for the dining table. In the United States, mulberry is not grown commercially causes fruits are so delicate and short-lived. This factor makes them exceptionally uncommon and sought after, particularly in California. Cafe chefs have been known to arrange for a considerable length of time at outside market to purchase these fashionable berries at $10 \$$ to $15 \$$ for a pound of fruit. In the Los Angels zone, some Iranian immigrants have even depended on planting their own mulberry plantations, so that, they will have simple access to their preferred fruit. The berries are sensitive and in this manner should be taken care of cautiously they do not break open, 
because the stain does not wash out easily. In Azerbaijan, during the off season of year, mulberry fruit are appreciated as mulberry syrup concentrates known as doshab and bakmaz. Moreover its sweet taste, fruits are additionally utilized as a medicine to secure against liver, gall bladder and heart disease (Alakbarov and Aliyev 2000). A well ripened fruit has a mouthwatering sweet taste with a wonderful flavor. Its chemical composition has been depicted in Table 1. Because of extremely high nutritional value, mulberry fruits are utilized for the medical advantages of peoples (Singhal et al. 2003, $2005 \mathrm{a \& b}$ ). In addition, fruit contains nutrient supplement of main importance in human digestion (Akbulut and Musazcan 2009). In black mulberry (M. nigra) fruits (Koyuncu 2004) there is malic acid in the range of $35.4-198.5 \mathrm{mg} / \mathrm{g}$ followed by citrus acid (5.5 - $23.4 \mathrm{mg} / \mathrm{g}$ ). Tartaric acid, oxalic acid and fumaric acid were at a level of $4.16,0.62$ and $0.019 \mathrm{mg} / \mathrm{g}$, respectively. In India, usage of mulberry leaf in making different foodstuff like tea, pakoda, dhokla and cakes has likewise been attempted and seen high rate of acceptability due to high nutritive value and taste (Srivastava et al. 1997). The fresh mulberry leaves are also used as a vegetable purpose in China.

Table 1. Nutritional value of mulberry fruits (Singhal et al. $2009 \mathrm{a} \& b$ )

\begin{tabular}{lc}
\hline Chemical constituents & Quantity \\
\hline Carbohydrates & $7.8-9.0 \%$ \\
Protein & $0.5-1.4 \%$ \\
Fatty acids (linoleic, stearic and oleic in seeds) & $0.3-0.5 \%$ \\
Free acid (mainly malic acid) & $1.1-1.18 \%$ \\
Fiber & $0.9-1.3 \%$ \\
Ash & $0.8-1.0 \%$ \\
Moisture & $85-88 \%$ \\
Calcium & $0.17-0.39 \%$ \\
Potassium & $1.0-1.49 \%$ \\
Magnesium & $0.09-0.10 \%$ \\
Sodium & $0.01-0.02 \%$ \\
Phosphorus & $0.18-0.21 \%$ \\
Sulpher & $0.05-0.06 \%$ \\
Iron & $0.17-0.19 \%$ \\
Carotene & $0.16-0.17 \%$ \\
Ascorbic acid & $11.0-12.50 \mathrm{mg} / 100 \mathrm{~g}$ \\
Nicotinic acid & $0.7-0.8 \mathrm{mg} / 100 \mathrm{~g}$ \\
Thiamine & $7.0-9.0 \mu \mathrm{g} / 100 \mathrm{~g}$ \\
Riboflavin & $165-179 \mu \mathrm{g} / 100 \mathrm{~g}$ \\
\hline & \\
\hline
\end{tabular}




\subsection{Mulberry as animal feed}

Shortage of land especially the grazing land to graze animals becomes a common phenomenon is most of the developing countries mainly because of quick industrialization, deforestation and increment in population. In Bangladesh, there is no exception. Therefore, the families who endeavored to make animal farm an essential movement has suffered. The mulberry rich in protein substance can be successfully utilized as animal feed. Mainly, leaves and entire shoot of mulberry are utilized to take care of the young and late matured instars during silkworm raising. Be that as it may, the mulberry leaf stalks and extras (like twigs and shoots) considered as wastage during this procedure can serve as nice feed for dairy animals, sheep and different lives stock. Furthermore, mulberry being a hardy plant can be grown in infertile land, along the side of the road and trench etc. In this manner it can fill the dual purpose rendering animal farming a productive business ventures to the little and marginal farmers and in effective management of scant land assets. Mulberry feed with balanced nutritive compositions of $\mathrm{N}, \mathrm{Ca}$ and P served as great animal feed (Majumdar et al. 1967). Rao et al. (1971) found that the increment in body weight and milk production in animal fed with left over mulberry leaf stalk. Deshmukh et al. (1993) found an empowering result (like quicker growth rate and better quality flush) when rabbits were fed with mulberry as the major feed stuff in the diet. Additionally, improvement in the yolk colour, increment in vitamin $\mathrm{k}$ and betacarotene has been found in the eggs of poultry birds feed with mulberry leaf meal (Sudo et al. 2000). Machii (2000) proposed an integrated poultry farming model with mulberry garden highlighting the advantageous impacts of poultry chicks in natural weeding and production of organic fertilizer while the minimal cost mulberry leaf meal rich in protein content in increasing quantity of poultry items, in this manner sparing time, labor and expenditure.

\subsection{Mulberry for other purposes}

Mulberry tree is utilized in food and chemical industries (Hua et al. 2007). The food added substances and beautifiers produced using mulberry leaf and fruit have been accessible in the market. A unique edible carbon produced using carbonization of mulberry root and stem has been generally utilized as food added substance. Recombined wood sheets and bars produced using mulberry branch can be utilized to substitute wood logs for making sections of flooring, door frames, and wooden models of structures, furniture, and parts of wooden structures. Mulberry branches substitute different woods or cotton seed structures for creating different palatable organisms, for example, mushroom, Lentinus edodes, agaric, Ganodorma lucidum, Flammulina velatipes, and Pleurotus ostreatus. Then, it is an amazing crude material for paper making and dynamic carbon production. Mulberry branch has very high unit ignition value, being a nice biomass fuel. Mulberry twigs are utilized to make healthy skin specialist. Mulberry bark fiber has nice attributes of normal fiber, being acceptable crude material for making high rank paper (He et al. 2007, Lin et al. 2008, Dai et al. 2009, Qin et al. 2010).

\section{Environmental importance of mulberry}

Quick industrialization combined with increment in population number has antagonistically affected on environment. Global warming, occurrences of natural calamities (like flood and drought etc.), sudden soil erosion, high rate of disease outbreak are some of the phenomena assumed to have direct results with environmental pollution. Mulberry has a few significant trademark highlights and found to be helpful in controlling environmental pollution (Jian et al. 2012). For example, mulberry cultivation found encouraging results about improving air quality, increasing water maintenance capacity, remediation of heavy metals from polluted soils, atmosphere and nurturing useful soil micro flora and fauna (Lu et al. 2004, Yao et al. 2004, Chen et al. 2006). This section shows environmental significance of mulberry to relieve the challenges emerged because of environmental pollution. 


\subsection{Improvement of air quality and microclimate condition}

Mulberry could improve the air quality for its strong photosynthesis, fast growth and high biomass. One hectare of mulberry could absorb 1 ton of carbon dioxide one day and release of 0.73 tons of oxygen, which could be utilized by 1000 people for breathing (Tan et al. 2010). However, Qin et al. (2010) reported that 1 hectare (ha) of mulberry could absorb carbon dioxide 49.29 tons a year and release oxygen about 35.85 tons through preliminary estimate (Qin et al. 2010, Jiang et al. 2017). Mulberry trees acts as great carbon sink plants. According to the data, 1 ha mulberry trees were able to absorb about $6.24 \times 10^{4} \mathrm{~kg}$ of $\mathrm{CO}_{2}$ and released $4.60 \times 10^{4} \mathrm{~kg}$ of $\mathrm{O}_{2}$ each year (Jian et al. 2012). Mulberry is a perfect tree species for city landscaping due its great features in tree structure, leaf colour, development pattern, diligence and resistance. Mulberry is drought and flood tolerance. Furthermore, mulberry leaves have ability to absorb air pollutants for example $\mathrm{Cl}, \mathrm{HF}, \mathrm{SO}_{2}$. Mulberry is a first class tolerance tree species against sulfur dioxide pollution. It has likewise high tolerance from chlorine pollution. It tends to be planted along waterway sides, at field edges, on slopes, at garden corners, alongside of the road, public parks and other recreation places. The gardener's plant mulberry along the boundaries of apple plantation with the aims that rats do not damage their apple trees and it is demonstrated right since mulberry roots discharge a few synthetic compounds which kill the rodents. Mulberry plants are developed as road trees in certain urban areas. Lu et al. (2004) revealed that soil temperature of terrace land with mulberry embankment was $0.8-1.0^{\circ} \mathrm{C}$ higher than that without it during raining period of July to August. This ensures mulberry attempts to optimize the soil temperature depending on ecological conditions and thus keeps the favorable conditions to promote development and increment in yield of the crop. The $0-20 \mathrm{~cm}$ earth temperature was $1.7^{\circ} \mathrm{C}$ lower and the most extreme water holding capacity of the soil was 20.57\% higher (Xiao and Shi 2006). Mulberry embankment reduces air temperature and increment air humidity. It likewise increment air temperature while the climate went to cold. The mulberry trees were planted in the ridges of the terrace land for a long time, compared to agriculture land without mulberry planting, erosion trench of the land with mulberry embankment were $35.7 \%$ less, $59.2 \%$ shorter, $61 \%$ smaller and $64 \%$ shallower (Liu et al. 2001).

\subsection{Adaptability to soil, water conservation and consolidation}

Mulberry trees have high adaptability to soil. Mulberry has very hardy root system. Its root structures an incredibly crossed and thickly arrange in soil. Mulberry plantation is highly capable of suppressing sand storm and conserving water and soil. Mulberry trees can flourish in deep, permeable and fertile soil yet additionally grow in infertile soil with poor supplements (Han 2007). According to Nan et al. (2011) soil shear quality was expanded from $75.2 \mathrm{kPa}$ to $138.4 \mathrm{kPa}$ while soil layer was developed from $0-10 \mathrm{~cm}$ to $30-40 \mathrm{~cm}$ in mulberry field. For example, the yearly spillover volume was decreased by 38 and $91 \%$ under the 5 and 10 year old mulberry bush belt individually than the agricultural slope land. Mulberry root structure can viably improve the shear strength of purple soil and increment against erosion capacity of soil. Mulberry is highly capable of drought tolerance and other natural hazards. It is additionally very effective in resisting wind and combining sand and soil. At present mulberry, has been utilized as a biological tree species for water and soil conservation and management of natural environment. Under pH value of 4.5-8.5 and salt substance $0.2 \%$ they still develop normally (Su 1998). That is the reason of mulberry trees has wide distribution and vigorous growth. Mulberry being a tree species with best growth after rise of the hydro fluctuation belt (He et al. 2007). Mulberry trees can resist chilling and freezing of $-30^{\circ} \mathrm{C}$ and persevere through high temperature of $40^{\circ} \mathrm{C}$ (Zhao 2009).

\subsection{Survivability to drought and water logging condition and wide genetic plasticity}

Mulberry trees have very hardy survivability and vitality. For instance, mulberry can develop well under regular dry and semi-arid desert region with yearly rainfall under 300-600 mm. Dai et al. (2009) revealed 
higher capacity of mulberry to adjust in desert zone with yearly rainfall under $150 \mathrm{~mm}$. Investigations indicated that adult mulberry trees could get survive from an immersion of $20 \mathrm{~d}$ during their development period. This is exceptionally rare among other xerophytic plants. Mulberry trees have very hardy continuance to water logging in dormant stage. Mulberry trees have hardy vitality. Owing to long period natural and artificial determinations mulberry ecotypes with various drought tolerance features have been distinguished. Under abundant soil moisture supply the transpiration coefficient of mulberry trees was 350-450 (Lv 2008). Under drought stress net photosynthetic rate, transpiration rate and water usage efficiency of mulberry leaves were decrease (Ji et al. 2004). The wilting coefficient of some drought tolerance mulberry varieties is 9, being lower than that of wild apricot (13), white elm (13) and poplar (13), exhibiting that mulberry adjusts to dry climate (Hu and Zhou 2010). Mulberry trees demonstrated to have wide genetic plasticity to adjust in changed agro-climatic condition. Dormant mulberry trees have the most resistance against chilling (Yao et al. 2004, Chen et al. 2006). This very nature of hardy characteristic feature of mulberry is proving through its dissemination pattern over the world ranging from temperature to tropical.

\subsection{Improvement of vulnerable ecological environment}

Mulberry planting in edges of terrace land has critical impacts in preventing soil erosion, water preservation, and soil resources and improving soil supplements. Contrasted with psammophytes, for example, Salix mongolica and Caragana korshinskii, mulberry trees on edges of terrace land adequately decrease runoff volume and soil erosion, reduce soil nitrogen runoff loss, and increment soil moisture usage ratio (Wani et al. 2017). The combination of mulberry and grass alleviate erosion of rainwater effectively intercept surface overflow on the slope, and change surface spillover into underground drainage. In the meantime, the fallen leaves and shoots spread the soil to increase soil moisture containment and fertility, giving adequate water and nutrient supply for mulberry development. This cultivation pattern has played significant role in water controlling and soil erosion, collecting rainfall water, increasing soil moisture containment, and gathering manures. According to examination, mulberry intercropped with grass on back side of level trench could reduce soil erosion by 124.5 tons per hectare, increment moisture substance of $50-100 \mathrm{~cm}$ soil layer by $13 \%$ $15 \%$, and increment organic substance content by $3 \%$ (Wani et al. 2017). Mulberry is very successful in preventing wind and consolidating sand. In dry and semi-dry territories, wind erosion is the essential factor that causes land desertification. Mulberry clusters are developed in bush structure on sand plots of a huge territory partitioned according to landform. Mulberry cluster is very successful in preventing wind and consolidating sand. In arid and semi-dry zones, wind erosion is the essential factor that causes land desertification. Mulberry clusters are developed in bush structure on sand plots of a huge region partitioned according to landform. The cluster has high tillering capacity. Their shoots can be bent into sand and recover roots to shape new plantlets to extend outwards. Mulberry clusters have extremely hardy root structure. Root structure consumes a room 7.9 times to that of tree crown, acquiring a generally excellent impact in preventing wind and consolidating sand. Mulberry trees are frequently grown as protection forest. Mulberry has very much developed root structure and extended crown, can reduce wind velocity, repressing wind and sand movement, and protecting crops in farmland. According to records cotton crop in farmland with defensive mulberry endured lost yield by $47.57 \%$, wheat by $23.03 \%$ and corn by $44.43 \%$, while cotton, wheat and corn crops in farmland without defensive mulberry were crushed and lost productivity by over 90\% (Wani et al. 2017).

\subsection{Restoring the fertility of soil}

Mulberry plantation is a best source of biomass production as well. It is possible to get more than 20 tons of firewood and more than 40 tons of mulberry leaves from one hectare per year, which makes extraordinary potential for production of organic manure. The left over mulberry from silkworm raising are being gathered 
and converted into compost, which is then utilized as organic manure. It is realized that utilization of organic manures prompts soil oxidation. Commonly, deviations in the acidity of soil from marginally acidic or impartial status lead to an imbalance of supplements accessible to plants and abuse of valuable soil microorganisms. Majority of cultivated plants, including mulberry, and helpful soil microorganisms develop well at low soil acidity (pH $6.5-7.0$ ). It is prescribed to include dolomite limestone into soil for balance of it super acidity. Practice appears, that use of limestone is too expensive for farmers (around 8000 USD/ha per 3 years) (Homidy and Papaskiri 2017). Other than that, the mineral limestone does not contain enough fundamental vital components for a plant. In this specific situation, the wood ash which has been widely utilized as a fertilizer since ancient times, particularly in those countries, where wood was in wealth, deserves a mention as an alternative to limestone.

\subsection{Mulberry in phytoremediation}

Phytoremediation is one of the best strategies to remediate heavy metals in soils. Mulberry can possibly remediate heavy metals polluted soils (Zhou et al. 2015). The developed root structure of mulberry is useful to absorb soil nutrients, to a certain extent additionally conductive to the absorption of metals in the soil (Jothimani et al. 2013). Heavy metals like $\mathrm{Pb}, \mathrm{Cd}$, Cu primarily are remediated through various specious of mulberry.

\section{Medicinal importance of mulberry}

Nevertheless, global silk industry, which had been concentrating on silk production only, recently exchanged its market for providing significant enhancements and raw materials for medicine. Mulberry fruit juice to dispose of contaminations from the body and to cure heart problems, dried fruit powder works as an antimutagen which can inhibit the mutation of healthy normal cells into cancerous cells (Nazim et al. 2017). Various parts of the mulberry plants are utilized in various ayurvedic drugs like as from the leaves unique type of tea is made which is utilized to control blood pressure. The root bark is utilized in purgative and anthelmintic medicines. The fruit juices are utilized to cure mouth ulcers, fever, heart, throat, stomach related, visual perception, iron deficiency, unsteadiness, a sleeping disorder, hepatitis, constipations, and so on like issues. Mulberry juices help in weight reduction, builds immunity, enhance appetite, increment hair development, alleviate tiredness and exhaustion, control extreme thirst. The important medicinal properties utilizing mulberry plant parts are described below accordingly.

\subsection{Medicinal importance of mulberry leaves}

Mulberry leaves are rich in calcium, phosphorus, magnesium, vitamins like B, C and $\mathrm{K}$. They additionally contain cancer prevention agents especially the anthocyanins and the flavonoids quercetin and kaempferol. The leaves contain 18 amino acids viz. phenylalanine, leucine, valine, tyrosine, proline, alanine, glutamic acid, glycine, serine, arginine, aspartic acid, cystine, threonine, sarcosine, gamma-amino-butyric acid, pipecolic acid, and 5-hydroxy pipecolic acid. The leaves are additionally a decent source of ascorbic acid. The medicinal properties of mulberry leaf are perceived for its diuretic, blood sugar and blood pressure reducing impacts. The leaf extract of white mulberry $(M$. alba) has been studied against the Indian Daboia russelii venom initiated local and systemic impacts. The extract totally nullified the in vitro hyaluronolytic and proteolytic activities of the snake venom (Chandrashekara et al. 2009). New pharmacological advantages of mulberry leaf against serious diseases like Alzheimer's disease, atherosclerosis, hyperlipidemia and etc. have been reported. 


\subsubsection{Against Alzheimer's disease, hyperlipidemia and Prevention of Atherosclerosis}

Lyengar (2007) proposed that mulberry extract give viable treatment to Alzheimer's disease through inhibition of amyloid beta-peptide (1-42) fibril formation and attenuation of neurotoxicity prompted by amyloid betapeptide and further affirm that mulberry leaf contains anti-oxidative substance that assists with prevent atherosclerosis and some flavonoids that are successful in controlling hyperlipidemia.

\subsubsection{Mulberry tea}

A unique tea called mulberry tea is produced using mulberry leaves. It is without caffeine. Mulberry tea has the beneficial outcomes of calming liver, improving visual perception and sharpens the hearing, clearing wind-heat, being a healthcare drink suitable to all ages (Wang et al. 2011). Besides it alleviates colds, coughs, throat infections, expected to prevent oxidation of cholesterol consequently keeping the arteries free from fat stores and subsequently solidifying of arteries. In Iran, dried mulberries are utilized as a sugar in black tea. After a sip of tea, dried mulberry fruit are eaten to sweeten the mouth (Nazim et al. 2017).

\subsection{Medicinal importance of mulberry fruits}

\subsubsection{Anti-obesity of mulberry fruit drink}

Obesity is characterized as irregular or excessive fat collection that surviving a hazard to health. An obese individual has aggregated so much body fat ratio that it may negatively affect their health. Obesity is connected with the diabetes, hypercholesterolemia, hyperlipidemia, hepatic steatosis, and atherosclerosis and decline the amount of sugars absorbed has consequences for body weight. A super fruit drink, full of antioxidant is prepared from pure mulberry fruits. It is a decent source of resveratrol which is considered to be gainful for heart health. The drink suppresses the hunger, which is the reason it has been accounted for as a valuable drink against obesity (Fairjuice 2008). Oh et al. (2010) conducted a short report on mice and showed antagonistic activity of mulberry extract on melanin concentrating hormone receptor, which help in decline in body weight. They likewise proposed that ethanolic extract got from mulberry leaves indicated antiobesity activity on diet-induced mice.

\subsubsection{Prevent cardiovascular disease of mulberry fruits drink}

Cardiovascular disease (CVD) is a non-transferable disease, however it is a significant public health problem worldwide which most is found in developing countries, around 80\% (WHO 2014). High cholesterol in the blood is a significant hazard factor for atherosclerosis that prompts different diseases, for example, coronary heart disease and stroke in the future. WHO has suggested that satisfactory consumption of fruit and vegetables ( 5 standard parts for every day or about $400 \mathrm{~g}$ every day) can prevent chronic disease including cardiovascular disease, hypertension, diabetes and cancer. Food consumption controlling is the first technique used to treat and to prevent the cardiovascular disease. Berries fruits are significant as the source of vitamins, minerals, fiber and phytochemical compounds, for example, anthocyanin (Kaewruang et al. 2011). Freeze-dried mulberries are contained higher polyphenols anthocyanins and quercetin than fresh mulberries around 5-10 times (Pansuwan et al. 2008). They can reduce blood cholesterol, inflammation, and cell antioxidant (Zafra-Stone et al. 2007). Ripe mulberry fruits are red to purple-dark. They are more in antioxidant than nutrient $C$ and $E$ twice. Antioxidants can reduce the damage of oxidants and reduce cholesterol in the blood (Castañeda-Ovando et al. 2009). A few tests, in both in vitro and animal, were discovered that mulberry can reduce an accumulation of fat inhibits the oxidation response of LDL cholesterol and improve the capacity of enzymes that are antioxidants (Liu et al. 2008, Ou et al. 2011). Fresh mulberry fruits are easily bruised after harvesting and can be kept for just a short duration. Consequently, in 
this examination, freeze-dried mulberry fruits were utilized because it still has antioxidants and high nutritional value that similar to in fresh mulberry fruits and could extend for longer storage. Moreover some previous examinations indicated that mulberry influenced on blood lipid levels was restricted just in vitro and animal studies only, while there was no studied in a human before on the effects of mulberry consumption on the changing of lipid levels antioxidants and inflammation in the blood.

\subsubsection{Improve human immune system of mulberry fruits drink}

Modern medical investigations show that mulberry fruit is utilized to increment the percentage of macrophage and the phagocytic coefficient, promote transformation of lymphocytes, and improve T-cell mediated immune capacity. Mulberry fruit can clearly help the development of hematopoietic cells, encourage the recovery of injured and reduce red blood cells and hemoglobin proteins to normal level inside a short period, and promote the recovery of hematopoiesis (Wani et al. 2017). The resveratrol existing in mulberry fruit can stimulate the expression of some human genes to inhibit the growth of cancerous cells, to prevent cell mutations caused by carcinogen, and to release hydrolyses from lysosome to dissemble cancerous cells (Du et al. 2007).

\subsubsection{Huge amount of amino acids and vitamins contain in mulberry fruits}

Fresh mulberry fruit contains 16 types of amino acids, 7 types of vitamins, minerals, for example, zinc, magnesium, calcium and microelements which are insufficient in human body. It additionally contains carotene, pectin and cellulose also. In addition, during the development time of mulberry fruit normally no pesticide is applied in mulberry field. Henceforth, mulberry fruit is a type of perfect "green food" (He et al. 2005). Mulberry fruit tastes sweet and delicious. It is good to the internal organs and the joints of human body. It has different healthcare and medicinal impacts, for example, nourishing liver and benefiting kidney, consolidating yin and nourishing blood, alleviating rheumatism and treating dizziness, and promoting saliva generation, and releasing thirst.

\subsubsection{Mulberry fruit powder}

Mulberry fruit powder advances healthy cholesterol and controls carbohydrate assimilation in the human body (Nazim et al. 2017). It is believed to prevent heart disease, cancer and various other diseases. It works as an anti-mutagen which can inhibit the mutation of healthy normal cells into cancerous cells (Hou 2003).

\subsubsection{Mulberry fruit wines}

Mulberry wine is acquired from over-ripened and sour mulberry fruits (Ehow 2009). The wine has a sweet taste. It has been discovered that a glass of mulberry wine a day disposes of oxides and fecal buildup from the body which can help make the body slim. The wine made by immersing the mulberry in grape wine works in as medicine for weakness after disease that can likewise be utilized to tonify masculine vitality. Besides it is believed that little portion of the wine secures against heart and stomach disease (Alakbarov and Aliyev 2000). In Europe mulberry fruit wine is well known as a ladies drink (Nazim et al. 2017).

\subsubsection{Fruit pigments as dietary modulators}

Wrolstad (2001) reported that mulberry fruits contain anthocyanins like cyaniding-3-rutinoside and cyaniding3-glucoside. He also reported that these pigments hold potential for use as dietary modulators, besides this they are easily extractable and incorporated into the aqueous food systems, so, they are also used as natural food colorant. 


\subsubsection{Mulberry fruits in pharmaceutical industry}

The mulberry fruits are utilized for different drug properties such as for balancing internal secretions and enhancing immunity (Kumar and Chauhan, 2008). However, this they are also utilized to treat urinary disorders, tinnitus, dizziness, constipation, sore throat, fever etc. The fruits of $M$. alba have a cooling and laxative property and are utilized in throat infection, dyspepsia and melancholia (Jain and De Filipps 1991). Fruit juices check thirst, cool the blood, reduce high fever and works as a good appetizer. Fruits are likewise utilized for loss of appetite, flatulence and for controlling intestinal parasites for example tapeworm. Mulberry fruits are revealed as antidiabetic with antioxidative properties (Kim et al. 1998). Hong et al. (2004) revealed that mulberry fruit strengthens the antioxidative defense system and reduces damaging oxidative substances in the erythrocytes of diabetes induced rats.

\subsection{Medicinal importance of mulberry stem}

Mulberry stem can likewise be utilized in medicines. The stems are antirheumatic, hypotensive, diuretic etc. Singh and Ghosh (1992) revealed that the stem bark of mulberry is having laxative and vermifuge like properties. A color of the bark is utilized to mitigate toothache.

\subsection{Medicinal importance of mulberry root}

Mulberry roots are one of the significant constituents of medicine named, "Glucosidase" which is utilized in hypertension, other than the roots are utilized in drugs having purifying and anthelmentic properties. Shivakumar et al. (1995) revealed that root juices of mulberries agglutinates the blood and is helpful in killing the worms in stomach related tract. Root bark of black mulberries ( $M$. nigra) contains calcium malate, tannins, unsaturated fats phytobaphenes, sugar, phytosterol, ceryl alcohol, and phosphoric acid. Thus, in light of these very properties bark have laxative and vermifuge like properties, other than it reduce the glucose level in diabetic patients. The root bark extract of black mulberries (M. nigra) contain deoxyjirimycin (DNJ), an alkaloid which is said to have active against AIDS virus. Then again, root bark of $M$. alba is utilized in traditional Chinese drug named as "Sang bai Pi, which is utilized to cure cough, asthma and various different disease. The ethanolic extract of "Sang Bai Pi" have been found to contain flavnoids viz. Morusin, Mulberrofuran D, G, K and Kwanon G, H, of which Morusin and Kwanon $\mathrm{H}$ indicated positive activity against HIV (Shi-De et al. 1995) and Morusin inhibits tumor promotion (Shigeru et al. 1989, Nazim et al. 2017).

\section{Future prospects}

The mulberry leaves are broadly utilized for feeding and raising of the silkworm (Bombyx mori) for the production of silk yarn. It is an amazing tree species with both environmental and economic advantages for water and soil conservation and ecological environment development. In future, mulberry environmental industries of various patterns will be built up according to the local land condition and market demand in various environmental zones. Through optimized and comprehensive usage of mulberry resources, a positive feedback system will be built up. That is to accomplish improvement of environmental impact and amplification of economic advantage of mulberry environmental industry. It is rich sources of flavonoids and different compounds that demonstrated antimicrobial potential and free radical scavenging activity. Because of its pharmacological properties, all parts of plant are utilized as medicine. Mulberry plants contain moranolin (DNJ), moran (glycopeptides), hydrophobic flavonoids (flavones and flavonone) and 2-arylbenzofuran which play main role in hypoglycemic activity. The pharmacological properties of $M$. alba including antiplatelet, anxiolytic, against asthmatic, anthelmintic, stimulant, antidepressant, cardio protective and immunomodulatory activities. Clinical trials on the proficiency of mulberry extracts in reducing blood glucose and cholesterol levels and upgrading psychological capacity have been led. The photochemistry and pharmacology of the various parts of the mulberry tree present its traditional and current uses as feed, food, 
beautifying agents, and medicine. Recently separated three new alkaloids, mulbaines A, B and C. Methanolic extract of mulberry leaves shows effective cytotoxic conduct against cancer cells. They distinguished numerous compounds like Kuwanon S, 8-granilapigenin, Ciclomulberrin, Ciclomorusin, Morusin atalantoflavones, and kaempherol with the activity strong cytotoxic cell lines HeLa, MCF-7 and Hep3B. Directed a short term report on root bark of $M$. alba and separated a flavanics for example glycoside, 5, 2dihydroxiflavanone-7, 4-di-O-D-glucoside, which prevents cell proliferation of human ovarian cancer cell HO8910. In this way we recommend that mulberry is one of the most beneficial plants in Bangladesh as well as in the world and advance research is needed for food, health and environmental purpose using mulberry plants in future.

\section{Summary and Concluding remarks}

Mulberry silk contributes around $90 \%$ of the total worldwide raw silk production and it is an exceptionally economic activity for the mostly rural people. Moreover the usage of mulberry leaves as silkworm feed; it is being utilized for some different purposes also. It is a quickly developing woody plant described by profound roots, flourish leaves, high tolerance from pollution, wind, sand, drought, and salinity with strong adaptability and simple cultivation. Thousands of years of experiences in mulberry cultivation and silkworm rearing have accumulated rich achievements in mulberry genetic resources, biological characters, and cultivation technology and industry development. At the present, environmental safety has gotten one of the valuable components of natural safety and environmental mulberry industry has a decent opportunity for development. The extract from various plant portions of mulberry proved to be useful in securing liver, improving visual perception, encouraging release of pee, lowering of blood pressure, against diabetic and controlling weight in human as well as animal models. For the eternal health, longevity and cure, to release pain and discomfort, scent, flavor and food, everywhere throughout the world humankind depend upon the plants to fulfill their needs. Medicinal plants still play valuable role in rising and developing countries. Mulberry plant is one of the significant traditional herbs widely utilized in medicine from hundreds of years prior.

\section{Acknowledgements}

Authors are grateful to the Ministry of Science and Technology (MOST), Govt. of Bangladesh for providing scholarships for this study. Grateful thanks also to Plant Biotechnology and Genetic Engineering Lab., Institute of Biological Sciences, University of Rajshahi for other supports of this study.

\section{References}

Akbulut M and Musazcan M (2009). Comparison of mineral contents of mulberry (Morus spp.) fruits and their pekmez (boiled mulberry juice) samples. International Journal of Food science and nutrition, 60: 231-239.

Alakbarov F and Aliyev I (2000). Silk Road-The origin of the mulberry trees. Azerbaijan International, 8: 3.

Andallu B and Varadacharyulu N (2002). Control of hyperglycemia \& Retardation of cataract by mulberry (Morus indica L.) leaves stroptozotocin diabetic rats. Indian Journal of Experimental Biology, 40: 791-795.

Andallu B and Varadacharyulu NC (2003). Antioxident role of mulberry cv. Anantha leaves in Morus indica (L) streptozotocin- diabetic rats. Clinica Chimica Acta, 338: 3-10.

Andallu B, Suryakantham V, Lakshmi Srikanthi B and Reddy GK (2001). Effect of mulberry (Morus indica L.) therapy on plasma and erythrosite membrane lipids in patients with type 2 diabetes. Clinica Chimica Acta, 314: 47-53.

Arfan M, Khan R, Rybarczyk A and Amarowicz R (2012). Antioxydant activity of mulberry fruit extract. International Journal of Molecular Science, 13: 2472-2480. 
Ashiru MO (2002). The effect of mulberry varieties on the performance of Chul Thai 5 silkworm race. Discovery and Innovation, 14(1): 77-83.

Best ML and Maier S (2007). Gender, culture and ICT use in rural south India. Gender, Technology and Development, 11(2): 137-155.

Bhatta R and Rao KA (2003). Women's livelihood in fisheries in coastal Karnataka, India. Indian Journal of Gender Studies, 10(2): 261-278.

Castañeda-Ovando A, De Lourdes Pacheco-Hernández M, Páez-hernández ME, Rodriguez JA and Galán-vidal CA (2009). Chemical studies of anthocyanins: A review. Food Chem., 113: 859-871.

Chandrashekara KT, Nagaraju S, Usha NS and Basavaiah KK (2009). Neutralization of local and systemic toxicity of Daboia russelii venom by Morus alba plant leaf extract. Phytotherapy Research, 23(8): 1082-1087.

Chen MG, Jin PH and Huang LX (2006). Energy analysis of mulberry-silkworm ecosystem in China. Chinese Journal of Applied Ecology, 17: 233-236.

Dai YW, Zhu H and Du HZ (2009). An evaluation on economic value and ecological function of mulberry resources. Journal of Protection Forest Science and Technology, 1: 78-80.

Datta RK (1988). Sericulture and rural Development. Tropical sericulture and prospects, proceedings of the international congress on Tropical Sericulture practices. February 18-23, Central silk Board, pp. 1-11.

Datta RK (2000). Mulberry cultivation and utilization in India. FAO Electronic Conference on Mulberryfor Animal Production (Morus L). http://www.fao.org/DOCREP/005/X9895E/

Delplanque M, Collet S, Gratta FD, Schnuriger B, Gaucher R, Robinson B and Bert V (2013). Combustion of Salix used for phytoextraction: The fate of metals and viability of the processes. Journal of Biomass Bioenergy, 49: 160-170.

Deshmukh SV, Pathak NV and Takalikar DA (1993). Nutritional effect of mulberry (Morus alba) leaves as sole ration of adult rabbits. Journal of World Rabbit Sciences, 1: 67-69.

Dewangan SK (2017). Employment Generation and Socio-Economic Change through Sericulture in Raigarh District, Chhattisgarh, India. Annals of Natural Sciences, 3(2): 32-42.

Doss SG, Chakraborti SP, Roychowdhuri S, Das NK, Vijayan K, Ghosh PD, Rajan MV and Qadri SMH (2012). Variability, heritability and genetic advance in mulberry (Morus spp.) for growth and yield attributes. Agri. Sci., 3(2): 208-213.

Du J, He ZD, Jiang RW, Ye WC and Xu HX (2003). Antiviral flavonoids from the root bark of Morus alba L. Journal of Phytochemistry, 62: 1235-1238.

Du ZH, Kou BY and Liu JF (2007). Study on medical and health-care utilization of sericulture resources. Journal of Anhui Agricultural Sciences, 35(14): 4216-4218.

Du ZH, Liu JF and Liu G (2001). Study on mulberry trees as both water and soil conservation and economy trees. Journal of Guangxi Sericulture, 38: 10-12.

Ehow (2009). How to make mulberry wine. Food and Drink.www.eHow.com

Eswarappa K (2000). Development and Change Due to Sericulture: A Village Study in Chittoor District. Hyderabad: University of Hyderabad.

Eswarappa K (2009a). Anthropology and Development in a Globalized India: Ethnography of Sericulture from the South. Newcastle Up on Tyne: Cambridge Scholars Publishing.

Eswarappa K (2009b). 'Socio-Cultural Dimensions of Sericulture: A Village Study from Andhra Pradesh'. In M. Moni and Suresh Misra (eds.), Rural India: Achieving Millennium Development Goals and Grassroots Development New Delhi, pp. 298-313.

Fairjuice (2008). Super fruit mulberry juice. Food and Beverage International, 13: 44.

Ganga G and Chetty JS (1991). An Introduction to Sericulture. Oxford and New Delhi: IBH Publishing Company. 
Ghosh A, Gangopadhyay D and Chowdhury T (2017). Economical and Environmental Importance of Mulberry: A Review. International Journal of Plant and Environment, 3 (2): 51-58.

Guo C, Yang J, Wei J, Li Y, Xu J and Jiang Y (2003). Antioxidant activities of peel, pulp and seed fractions of common fruits as determined by FRAP assay. Journal of Nature and Research, 23: 1719-1726.

Han SY (2007). The ecological value of mulberry and its ecological cultivation models for planting mulberry from eastern to western areas in Guizhou. Journal of Guizou Agrical Sciences, 35: 140-142.

He XB, Xie ZQ and Nan HW (2007). Developing ecological economy of sericulture and vegetation restoration in the water-level-fluctuating zone of the three gorges reservoir. Science and Technology Review, 25(23): 59-63.

He XM, Liao ST and Liu JP (2005). Progress of comprehensive utilization of mulberry resources and development countermeasure. Science of Sericulture, 31(1): 4-7.

Homidy HS and Papaskiri AN (2017). Efficiency of enrichment of fertility and regulation of soil acidity on growth and yield of mulberry. $8^{\text {th }}$ BACSA International Conference on Climate Changes and Chemicals- the New Sericulture Challenges, CLISERI, Sheki, Azerbaijan, April 02, pp. 54-55.

Hong JH, Ahn JM, Park SW and Rhee SJ (2004). The effects of mulberry fruit on the antioxidative defense systems and oxidative stress in the erythrocytes of streptozotocin induced diabetic rats. Nutritional Science, 7: 127-132.

Hou DX (2003). Potential mechanisms of cancer chemoprevention by anthocyanins. Current Molecular Medicine, 3: 149-159.

Hu J and Zhou JX (2010). Development and utilization of mulberry eco-industry in sand field. Beijing: Chinese Forestry Press, pp. 10-11.

Hua L, Zhang WQ and Zhao XF (2007). Antibacteria effect of aqueous extract of mulberry leaves. Shanghai Journal of Biomedical Engineering, 28(1): 16-18.

Jain SK and De-Filipps A (1991). Medicinal Plants in India. Reference Publications Inc. Algonac Michigan, 2: 438.

Ji XL, Gai YP and Mu ZM (2004). Effect of water stress on physiological and biochemical character of mulberry. Science of Sericulture, 30(2): 117-122.

Jian Q, Ningjia H, Yong W and Zhonghuai X (2012). Ecological issues of mulberry and sustainable development. Journal of Resources and Ecology, 3: 330-339.

Jiang Y, Huang R, Yan X, Jia C, Jiang S and Long T (2017). Mulberry for environmental protection. Pakistan Journal of Botany, 49(2): 781-788.

Jothimani P, Ponmani S and Sangeetha R (2013). Phytoremediation of heavy metals- A review. International Journal of Research Studies in Bioscience, 1: 17-23.

Kaewruang W, Wongareonwanakit S, Ingkaninan K and Wongthai J (2011). Antioxidant in different mulberry (Morus spp.) varieties. In: The Queen Sirikit Department of Sericulture, December 14-18 Chiangmai, Bangkok, pp. 304-310.

Kim SY, Park KJ and Lee WC (1998). Anti-inflammatory and anti-oxidative effects of Morus spp. fruit extract. Korean Journal of Medicinal and Crop Science, 6: 204-209.

Koyuncu F (2004). Organic acid composition of native black mulberry fruit. Chemistry of Natural Compounds, 40: 367-369.

Kumar SGR, Anantha, Raman KV, Magadum SB and Datta RK (1995). Medicinal values of mulberry. Indian Silk, 34: 15-16.

Kumar V and Chauhan S (2008). Mulberry: Life enhancer. Journal of Medicinal Plant Research, 2(10): 271-278.

Lin TB, Li YG and Lv ZQ (2008). Advances in the research and development on the synthesize utilization of mulberry resources. Bulletin of Sericulture, 39(3): 1-4.

Liu JX, Yao J and Yan BJ (2001). Effects of mulberry leaves to replace rapeseed meal on performance of sheep feeding on ammoniated rice straw diet. Small Ruminant Research, (39): 131-136. 
Liu LK, Lee HJ, Shih YW, Chyau CC and Wang CJ (2008). Mulberry anthocyanin extracts inhibit LDL oxidation and macrophage-derived foam cell formation induced by oxidative LDL. Journal of Food Science, 73: 113-121.

Lu M, Wang RQ and Qi XS (2004). Reaction of planting tree species on chlorine pollution in the atmosphere. Journal of Shandong University, 39: 98-101.

Lv HS (2008). Principles of Horticultural Science. Shanghai: Shanghai Science \& Technology Press, pp. 39-40.

Lyengar MNS (2007). Research Beliefs. Indian Silk, 29: 30-34.

Machii $H$ (2000). Evaluation and utilization of mulberry for poultry production in Japan, mulberry for animal production. Journal of Animal production and Health Series, 147: 237-247.

Majumdar BN, Momin SA and Kehar ND (1967). Studies on tree leaves as cattle fodder. 1. Chemical composition as affected by the stage of growth. Indian Journal of Veterinary Science, 37: 217-223.

Nan HW, He XB and Bao YH (2011). Influence of root system of Morus alba to shearing resistance of purple soil. Soil and Water Conservation in China, 8: 48-51.

Nazim N, Buhroo ZI, Mushtaq N, Javid K, Rasool S and Mir GM (2017). Medicinal values of products and by products of sericulture. Journal of Pharmacognosy and Phytochemistry, 6(5): 1388-1392.

Oh BK, Oh KS, Kwon KI, Ryu SY, Kim YS and Lee BH (2010). Melanin-concentrating hormone-1 receptor antagonism and antiobesity effects of ethanolic extract from Morus alba leaves in diet-induced obese mice. Phytother Res., 24(6): 919-923.

Ou TT, Hsu MJ, Chan KC, Huang CN, Ho HH and Wang CJ (2011). Mulberry extract inhibits oleic acid-induced lipid accumulation via reduction of lipogenesis and promotion of hepatic lipid clearance. Journal of Science Food Agriculture, 91: 2740-2748.

Pan G and Lou CF (2008). Isolation of an 1-aminocyclopropane-1-carboxylate oxidase gene from mulberry (Morus alba L.) and analysis of the function of this gene in plant development and stresses response. Journal of Plant Physiology, 165: 1204-1213.

Pansuwan S, Nuipirom W, Apinyanuwat S, Numphanon H and Jomduang S (2008). Study on product of mulberry freeze drying. Annual research report of sericulture, Bangkok, pp. 285-293.

Peng X, Yang B, Deng D, Dong J and Chen Z (2012). Lead tolerance and accumulation in three cultivars of Eucalyptus urophylla grandis: implication for phytoremediation. Environmental Earth Sciences, 67: 1515-1520.

Pérez-Gregorio MR, Regueiro J, Alonso-González E, Pastrana-Castro LM and Simal-Gándara J (2011). Influence of alcoholic fermentation process on antioxidant activity and phenolic levels from mulberries (Morus nigra L.). LWTFood Science and Technology, 44: 1793-1801.

Qin J, He NJ and Huang XZ (2010). Development of mulberry ecological industry and sericulture. Acta Sericologica Sinica, 36(6): 984-989.

Radhakrishna PG, Sekharappa BM and Manibashetty VG (2000). Silk and milk- an economic package for rural upliftment. Indian Silk, pp. 11-12.

Rahman MS and Islam SMS (2020a) Genetic variability and correlation studies of mulberry (Morus alba L.) genotypes in Bangladesh. Bangladesh Journal of Botany, 49(3): 685-691.

Rahman MS and Islam SMS (2020b) Genetic diversity analysis based on morphological characters in mulberry (morus spp.). Journal of Bio-Science, 28: 111-119.

Rao AS, Kumar MA and Sampath SR (1971). Studies on mulberry (Morus indica) leaf-stalkpalatability, chemical composition and nutritive value. Indian Veterinary Journal, 48: 853-857.

Sharma SB, Tanwar RS, Rini A, Singh UR, Gupta S and Shukla SK (2010). Protective effect of Morus rubra L. leaf extract on diet-induced atherosclerosis in diabetic rats. Indian Journal of Biochemistry and Biophysics, 47: 26-31. 
Sheng-Qin ZOU and Wu CHEN (2003). A review on chemical constituents, pharmacological activity and application of mulberry leaves. Journal of Chemical Industry of Forest Products, 1: 1-8.

Shi DM, Lu XP and Liu LZ (2005). Study on functions of soil and water conservation by mulberry hedgerow intercropping of purple soil slopping farmland in three gorges reservoir region. Journal of Soil Water Conservation, 19: 75-79.

Shi-De L, Nemec J and Ning BM (1995). Anti-HIV flavanoids from Morus alba. Acta Bot. Yunnanica, 17: 89-95.

Shigeru Y, Suganuma M, Fujiki H, Fukai T, Nomura T and Sugimura T (1989). Morusin, isolated from root bark of Morus alba L. inhibits of tumor promotion of teleocidin. Phytotherapy Research, 3(5): 193-195.

Shivakumar GR, Anantha, Raman KV, Magadum SB and Datta RK (1995). Medicinal values of mulberry. Indian Silk, 34: 15-16.

Singh KP and Ghosh PL (1992). Indian silk, 31: 16.

Singhal BK, Dhar A, Bindroo BB, Tripathi PM, Qadri SMH and Ahsan MM (2003). Medicinal utilities of mulberry and nonmulberry food plants of the silkworm. In: Recent progress in medicinal plants, phytochemistry and pharmacology II. Studium Press LLC, USA, Vol. 8, pp. 477-500.

Singhal BK, Dhar A, Khan MA and Bindroo BB (2005a). Utilization of sericultural byproducts as urgent need for sustainable sericulture. In: Govindan R, Ramakrishna N, Sannappa B and Chandrappa D (eds.) Progress of research in organic sericulture and seribyproduct utilization, Seri Scientific Publishers, Bangalore, pp. 211-226.

Singhal BK, Dhar A, Khan MA, Bindroo BB and Fotedar RK (2009a). Potential economic additions by mulberry fruits in sericulture industry. Plant Horti. Tech., 9: 47-51.

Singhal BK, Dhar A, Khan MA, Sengupta D and Dhar SL (2005b). Mulberry by-products utilization for sustenance of sericulture industry of Jammu and Kashmir. Proc. The $20^{\text {th }}$ Congress of the International Sericultural Commission, Vol. I Central Silk Board, Bangalore, pp. 152-156.

Singhal BK, Khan MA, Dhar A and Bindroo BB (2009b). New vistas for industrial exploitation of mulberry fruits in horticulture industry. Paper presented in International Conference on Horticulture (ICH-2009), PNASF, VEGINET, UAS, Bangalore, India, Abst. 1.4-06, p. 249.

Singhal BK, Khan MA, Dhar A, Baqual FM and Bindroo BB (2010). Approaches to industrial exploitation of mulberry (Mulberry sp.) fruits, Journal of Fruit and Ornamental Plant Research, 18(1): 83-99.

Srivastava S, Kapoor R and Srivastava RP (1997). Delicious delicacies from nutritious mulberry. Indian Silk, 39: 36-40.

Su GX (1998). Relationship between metabolic variation of active oxygen and salt tolerance of mulberry under salt stress. Journal of Soochow University, 14(1): 85-90.

Sudo M, Kuramoto $\mathrm{H}$ and Iso M (2000). Studies on functional poultry eggs. Effects of mulberry leaves on quantity of eggs. Bulletin Ibaraki Prefectural Poultry Experiment Station, 35 (in Japanese).

Sujathamma P, Savithri G and Kavyasudha K (2013). Value addition of mulberry (Morus spp). International Journal of Emerging Technologies in Computational and Applied Sciences, 5: 352-356.

Tan C, Feng $Y$ and Long $H$ (2010). The important role of mulberry in low carbon and ecological economy of China. Sichuan Canye, 1: 12-15.

Vijayan K, Tikader A, Weiguo Z, Nair CV, Ercisli S and Tsou CH (2011). Morus. In: Wild crop relatives: Genomic and breeding resources: Tropical and subtropical fruits, (Ed.): Kole, C. Springer Berlin Heidelberg, Berlin, Heidelberg, pp. 75-95.

Wang L, Gong T and Chen RY (2009). Two new prenylflavonoids from Morus nigra L. Journal of Chinese Chemistry, 20: 1469-1471.

Wang $Y$ and LO Björn (2014). Heavy metal pollution in Guangdong province, China, and the strategies to manage the situation. Frontiers in Environmental Science, 2: 9. 
Wang ZH, Wu Y and Zhang YZ (2011). Analysis on organoleptic quality and nutrient active ingredients of mulberry-leaf teas made by different processing techniques. Science of Sericulture, 37(2): 272-277.

Wani MY, Mir MR, Baqual MF, Ganie NA, Bhat ZA and Ganie QA (2017). Roles of mulberry tree. The Pharma Innovation Journal, 6(9): 143-147.

World Health Organization (2014). Global status report on non-communicable diseases. Geneva: WHO Press. https://www.who.int/nmh/publications/ncd-status-report.

Wrolstad RE (2001). The possible health benefits of anthocyanin pigments and polyphenolics, Linus Pauling Institute, Oregon State University, https://portal.nifa.usda.gov.

Yang X, Yang $L$ and Zheng $H$ (2010). Hypolipidemic and antioxidant effects of mulberry (Morus alba L.) fruit in hyperlipidaemia rats. Journal of Food Chemistry and Toxicology, 48: 2374-2379.

Yao F, Yu WZ and Yang XE (2004). Genotype resources and ecological adaptation of mulberry plants (Morus indica L.) and their application foreground. Bulletin of Science and Technology, 20: 289-297.

Zafra-Stone S, Yasmin T, Bagchi M, Chatterjee A, Vinson JA and Bagchi D (2007). Berry anthocyanins as novel antioxidants in human health and disease prevention. Molecular Nutrition Food Research, 51: 675-83.

Zhang M, Chen M, Zhang HQ, Sun S, Xia B and Wu FH (2009). In vivo hypoglycemic effects of phenolics from the root bark of Morus alba. Journal of Fitoterapia, 80: 475-477.

Zhao QD (2009). The peculiar village at edge of desert. Xinjiang Humanities Geography, 4: 78.

Zhou L, Zhao Y, Wang S, Han S and Liu J (2015). Lead in the soil-mulberry (Morus alba L.) silkworm (Bombyx mori) food chain: translocation and detoxification. Chemosphere, 128: 171-177.

(Manuscript received on 31 February 2020; revised on 12 April 2020) 